OPEN ACCESS

Edited by: Angel Lanas,

University of Zaragoza, Spain

Reviewed by:

Daniel Carpio,

Complejo Hospitalario de

Pontevedra, Spain

Zubair Khan

University of Texas Health Science Center at Houston, United States

*Correspondence:

Wei-Sheng Chung

chung.w53@msa.hinet.net; albertchung5325@gmail.com

\footnotetext{
Specialty section:

This article was submitted to

Gastroenterology,

a section of the journa

Frontiers in Medicine
}

Received: 02 February 2021

Accepted: 10 May 2021

Published: 02 June 2021

Citation:

Chung W-S, Chung S, Hsu C-Y and

Lin C-L (2021) Risk of Inflammatory

Bowel Disease Following Appendectomy in Adulthood.

Front. Med. 8:661752.

doi: 10.3389/fmed.2021.661752

\section{Risk of Inflammatory Bowel Disease Following Appendectomy in Adulthood}

\author{
Wei-Sheng Chung ${ }^{1,2,3 *}$, Sunny Chung ${ }^{4}$, Chung-Y Hsu ${ }^{5}$ and Cheng-Li Lin ${ }^{6,7}$ \\ ${ }^{1}$ Department of Internal Medicine, Taichung Hospital, Ministry of Health and Welfare, Taichung, Taiwan, ${ }^{2}$ Department of \\ Health Services Administration, China Medical University, Taichung, Taiwan, ${ }^{3}$ Department of Healthcare Administration, \\ Central Taiwan University of Science and Technology, Taichung, Taiwan, ${ }^{4}$ Department of Chemistry, Point Loma Nazarene \\ University, San Diego, CA, United States, ${ }^{5}$ Graduate Institute of Biomedical Sciences, China Medical University, Taichung, \\ Taiwan, ${ }^{6}$ Management Office for Health Data, China Medical University Hospital, Taichung, Taiwan, ${ }^{7}$ College of Medicine, \\ China Medical University, Taichung, Taiwan
}

Background: The appendix has a complicated immune function, and appendectomy may derange the immune system. Studies on the relationship between appendectomy and subsequent inflammatory bowel disease (IBD) have been inconsistent. We conducted a nationwide cohort study consisting of individuals who underwent appendectomy to evaluate the incidence and risk of ulcerative colitis (UC) and Crohn's disease (CD).

Methods: We identified patients aged $>20$ years who underwent appendectomy between 2000 and 2012 from inpatient claims of the National Health Insurance Research Database (NHIRD) and assigned them to the appendectomy cohort. Then, we randomly selected patients without appendectomy in the NHIRD and assigned them to the comparison cohort in a frequency-matched 1:1 ratio based on sex, age, and index year. We tracked down all participants until IBD diagnosis, death, or the end of 2013. Cox models were used to estimate the hazard ratio $(\mathrm{HR})$, and 95\% confidence intervals $(\mathrm{Cls})$ were used to compare the IBD risk between the appendectomy and comparison cohorts.

Results: The appendectomy and comparison cohorts in the study consisted of 246562 patients each. The appendectomy cohort exhibited a 2.23- and 3.48-fold higher risk of UC (adjusted $\mathrm{HR}=2.23,95 \% \mathrm{Cl}=1.59-3.12$ ) and $\mathrm{CD}$ (adjusted $\mathrm{HR}=3.48$, $95 \% \mathrm{Cl}=2.42-4.99$ ), respectively, than did the comparison cohort. UC and CD risks significantly increased in the appendectomy cohort regardless of whether appendicitis was present.

Conclusions: Our study suggests that appendectomy increases UC and CD risks irrespective of appendicitis.

Keywords: appendectomy, inflammatory bowel disease, ulcerative colitis, Crohn's disease, cohort study

\section{INTRODUCTION}

The human appendix is similar to a diverticulum of the cecum, which is considered a vestigial organ. Previously, the biological function of the appendix was unclear; therefore, it was surgically removed on inflammation. Clinicians consider appendectomy a safe and effective technique for managing appendicitis (1). In the United States, the lifetime appendectomy risks in men and women are 12 and $23 \%$ but the lifetime appendicitis risks are 8.6 and $6.7 \%$, respectively (2). In Taiwan, $10.8 \%$ of appendectomies were not related to appendicitis (3). 
The submucosa of the appendix contains numerous lymphoid follicular centers. In addition, complicated immune system cells are present in the mucosa (e.g., Treg cells, $M$ cells, and $\mathrm{T}$ and $\mathrm{B}$ cells) and submucosa (e.g., B lymphocytes, $\mathrm{T}$ lymphocytes, macrophages, centrocytes, and $\mathrm{CD} 4^{+} / \mathrm{CD} 8^{+}$cells) of the appendix $(4,5)$. Studies have indicated that the appendix interacts with intestinal flora and balances the intestinal immune system (4-7). The bacteria in the appendix may act as a biofilm inoculum of the intestinal commensal microbiome, which facilitates reinoculation of the proximal large bowel and terminal ileum. The complex immune system and a shelter for microbiome in the appendix can balance proinflammation and antiinflammation of the bowel and maintain homeostasis (4).

Inflammatory bowel diseases (IBDs) mainly consist of Crohn's disease (CD) and ulcerative colitis (UC), which cause prolonged inflammation of the digestive tract. IBDs considerably affect health-related quality of life and markedly increase health care costs $(8,9)$. The incidence of IBDs has increased steadily in Taiwan (10). The exact cause of IBDs remains unclear. In addition to genetics, the environmental composition of intestinal microbiome may play a role in uncontrolled gut inflammation (11). However, the relationship between appendectomy and IBD development has been controversial in Western countries (1214). Studies on the association of appendectomy with subsequent IBD risk are scant. Therefore, we conducted a nationwide cohort study to examine whether IBD risk is higher in the appendectomy cohort than in the non-appendectomy cohort.

\section{METHODS}

\section{Data Source}

The data for this study were obtained from the National Health Insurance Research Database (NHIRD). The Taiwan government launched a National Health Insurance Program (NHIP) in 1995. NHIP provides comprehensive medical care services to nearly all (99\%) residents in Taiwan. The health information, which includes claims of the inpatients and outpatients and medications prescribed, was recorded in the NHIRD. For patient privacy, the data were deidentified. In this cohort study, we used all inpatient data from 2000 to 2013 .

\section{Study Sample}

The present cohort study consisted of case and comparison groups. People who underwent appendectomy (International Classification of Diseases, Ninth Revision, Clinical Modification [ICD-9-CM] codes 47.0 and 47.1) were recruited as the case group.

We defined the first operation date of appendectomy as the index date. Patients with IBD diagnosis (ICD-9-CM codes 555 and 556) before the index date were excluded. The comparison group consisted of people without a history of IBDs and appendectomy. Participants aged $<20$ years were excluded from both the groups. Controls were matched with patients in the case group based on sex, age, and index year with a 1:1 ratio. All participants were followed from the index date to withdrawal from the NHIP, death, or end of the study (December 31, 2013).
TABLE 1 | Comparison of demographics and comorbidities between patients with and without appendectomy.

\begin{tabular}{|c|c|c|c|}
\hline & \multicolumn{2}{|c|}{ Appendectomy } & \multirow[b]{2}{*}{$p$-value } \\
\hline & $\begin{array}{c}\text { Yes }(N=246,562) \\
n(\%)\end{array}$ & $\begin{array}{c}\text { No }(N=246,562) \\
n(\%)\end{array}$ & \\
\hline Age, years & & & 0.99 \\
\hline $20-34$ & $94,814(38.5)$ & $94,814(38.5)$ & \\
\hline $35-49$ & 74,812 (30.3) & $74,812(30.3)$ & \\
\hline$>50$ & $76,936(31.2)$ & $76,936(31.2)$ & \\
\hline Mean $(\mathrm{SD})^{\dagger}$ & $43.3(16.7)$ & $43.1(16.9)$ & $<0.001$ \\
\hline Gender & & & 0.99 \\
\hline Female & $119,806(48.6)$ & $119,806(48.6)$ & \\
\hline Male & $126,756(51.4)$ & $126,756(51.4)$ & \\
\hline \multicolumn{4}{|l|}{ Comorbidity } \\
\hline CAD & $8,657(3.51)$ & 6,011 (2.44) & $<0.001$ \\
\hline Hypertension & 26,628 (10.8) & $13,128(5.32)$ & $<0.001$ \\
\hline Diabetes & $14,566(5.91)$ & 7,602 (3.08) & $<0.001$ \\
\hline Hyperlipidemia & $6,080(2.47)$ & $3,815(1.55)$ & $<0.001$ \\
\hline CVA & $6,764(2.74)$ & $5,462(2.22)$ & $<0.001$ \\
\hline Heart failure & $2,837(1.15)$ & $1,845(0.75)$ & $<0.001$ \\
\hline COPD & $4,237(1.72)$ & $2,758(1.12)$ & $<0.001$ \\
\hline CKD & 2,056 (0.83) & $834(0.34)$ & $<0.001$ \\
\hline Alcohol-related diseases & $2,250(0.91)$ & $1,282(0.52)$ & $<0.001$ \\
\hline Cirrhosis & 8,729 (3.54) & $4,529(1.84)$ & $<0.001$ \\
\hline Biliary stone & $6,167(2.50)$ & $3,070(1.25)$ & $<0.001$ \\
\hline
\end{tabular}

Categorical data were examined using a chi-squared test; ${ }^{\dagger}$ continuous data were examined using a t-test.

$C A D$, coronary artery disease; $C K D$, chronic kidney disease; COPD, chronic obstructive pulmonary disease; CVA, cerebrovascular disease; $S D$, standard deviation.

\section{Main Outcomes and Covariates}

The endpoint of this study was defined as IBD diagnosis (ICD-9-CM codes 555 and 556), including UC (ICD-9-CM code 556) and CD (ICD-9-CM code 555). We divided participants into 3 age groups: 20-34 years, 35-49 years, and $>50$ years. Some IBD-related medical comorbidities, including hypertension (ICD-9-CM codes 401-405), diabetes (ICD-9-CM code 250), hyperlipidemia (ICD-9-CM code 272), cardiovascular disease (ICD-9-CM codes 430-438), heart failure (ICD-9-CM code 428), chronic obstructive pulmonary disease (ICD-9-CM codes 491, 492, and 496), chronic kidney disease (ICD-9-CM codes 580-589), alcohol-related diseases (ICD-9$C M$ codes 291, 303, 305.00, 305.01, 305.02, 305.03, 571.0$571.3,790.3$, and V11.3), cirrhosis (ICD-9-CM code 571), and biliary stones (ICD-9-CM code 574), were considered potential confounding factors.

\section{Statistical Analysis}

A chi-square test was used for comparing the categorical variables between case and comparison groups. The mean age was examined using the student $t$-test. Then, we calculated the IBD incidence rates (per 10,000 person years) among the two groups. Hazard ratios (HRs) were estimated using a Cox proportional hazards model and adjusted using the 
TABLE 2 | Incidence and adjusted hazard ratio of inflammatory bowel disease based on sex, age, and comorbidities for patients with appendectomy compared with controls.

\begin{tabular}{|c|c|c|c|c|c|c|c|c|}
\hline \multirow[b]{3}{*}{ Variables } & \multicolumn{6}{|c|}{ Appendectomy } & \multicolumn{2}{|c|}{ Compared to control } \\
\hline & \multicolumn{3}{|c|}{ Yes } & \multicolumn{3}{|c|}{ No } & \multirow[b]{2}{*}{ Crude HR (95\% CI) } & \multirow[b]{2}{*}{ Adjusted $\mathrm{HR}^{\dagger}(95 \% \mathrm{Cl})$} \\
\hline & Events & PY & Rate $\#$ & Events & PY & Rate $\#$ & & \\
\hline All & 255 & $1,737,942$ & 14.7 & 87 & $1,766,861$ & 4.92 & $2.98(2.33,3.79)^{\star \star \star}$ & $2.78(2.17,3.55)^{\star \star \star}$ \\
\hline Ulcerative colitis (UC) & 116 & & 6.67 & 49 & & 2.77 & $2.40(1.72,3.36)^{\star \star \star}$ & $2.23(1.59,3.12)^{\star \star \star}$ \\
\hline Crohn's disease (CD) & 139 & & 8.00 & 38 & & 2.15 & $3.71(2.59,5.31)^{\star \star \star}$ & $3.48(2.42,4.99)^{\star \star \star}$ \\
\hline \multicolumn{9}{|l|}{ Gender } \\
\hline Female & 119 & 851,339 & 14.0 & 38 & 863,289 & 4.40 & $3.17(2.20,4.57)^{\star \star \star}$ & $2.95(2.04,4.26)^{\star \star \star}$ \\
\hline Male & 136 & 886,602 & 15.3 & 49 & 903,572 & 5.42 & $2.82(2.04,3.91)^{\star \star \star}$ & $2.64(1.90,3.67)^{\star \star \star}$ \\
\hline \multicolumn{9}{|l|}{ Age, years } \\
\hline$\leq 34$ & 101 & 713,152 & 14.2 & 29 & 704,429 & 4.12 & $3.45(2.28,5.21)^{\star \star \star}$ & $3.33(2.20,5.04)^{\star \star \star}$ \\
\hline $35-49$ & 64 & 553,971 & 11.6 & 13 & 560,303 & 2.32 & $4.98(2.74,9.03)^{\star \star \star}$ & $4.63(2.54,8.44)^{\star \star \star}$ \\
\hline$>50$ & 90 & 470,819 & 19.1 & 45 & 502,128 & 8.96 & $2.13(1.49,3.04)^{\star \star \star}$ & $1.81(1.26,2.60)^{\star \star}$ \\
\hline \multicolumn{9}{|l|}{ Comorbidity } \\
\hline No & 175 & 146,6719 & 11.9 & 63 & $1,628,953$ & 3.87 & $3.09(2.32,4.12)^{\star \star \star}$ & $3.12(2.34,4.17)^{\star \star \star}$ \\
\hline Yes & 80 & 271,222 & 29.5 & 24 & 137,908 & 17.4 & $1.69(1.07,2.67)^{\star}$ & $1.75(1.11,2.77)^{\star}$ \\
\hline
\end{tabular}

Rate" ${ }^{\#}$ incidence rate per 10,000 person-years; Crude HR, relative hazard ratio; Adjusted $H R^{\dagger}$, adjusted hazard ratio after control for age, sex, and comorbidities of CAD, hypertension, diabetes, hyperlipidemia, CVA, heart failure, COPD, CKD, alcohol-related diseases, cirrhosis, and biliary stone.

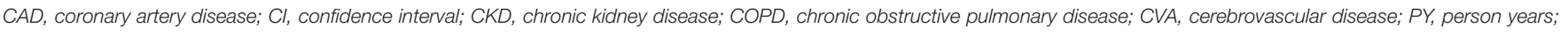
$S D$, standard deviation.

${ }^{\star} P<0.05,{ }^{\star \star} P<0.01,{ }^{* \star} P<0.001$.

variables of age, sex, and comorbidities into the multivariable Cox proportional hazards model. Furthermore, we analyzed the association between the follow-up period and IBDs. The cumulative incidences of IBDs in the 2 groups were estimated using the Kaplan-Meier method. Furthermore, the log-rank test was used to evaluate the difference between the two curves. The statistical significance level was represented by a $P$-value of $<.05$ for all tests.

\section{RESULTS}

A total of 493,124 participants were included in this study. The mean follow-up time for the appendectomy group was 7.05 ( \pm 3.91$)$ years, and that for the comparison group was 7.17 ( \pm 3.88$)$ years. The distribution of demographics and comorbidities between appendectomy patients and controls is presented in Table 1. The proportions of age groups and gender were not significantly different between the 2 groups. Most of the study population was in the age group of 20-34 years (38.5\%) and most participants were male (51.4\%). The mean age of the case group was 43.3 $( \pm 16.7)$ years and that of the control group was 43.1 (16.9) years. The proportion of patients with comorbidities was significantly higher in the appendectomy group than in the control group.

Table 2 shows the incidence and HRs of IBDs. The incidence rate of IBDs in the case group was 14.7 per 10,000 person years, and that in the comparison group was
4.92 per 10,000 person years. The IBD risk in patients with appendectomy was 2.78-fold higher than (95\% confidence interval $[\mathrm{CI}]=2.17-3.55$ ) that in people without appendectomy. Appendectomy increases UC risk by 2.23 times (95\% CI = 1.59-3.12). The adjusted HR of CD for appendectomy patients compared with controls was 3.48 (95\% CI $=2.42-4.99)$. Appendectomy increased IBD risk regardless of gender or age groups. The adjusted HR of IBDs was higher in patients with appendectomy than in patients without appendectomy irrespective of comorbidities (adjusted HR $=3.12,95 \% \mathrm{CI}=$ 2.34-4.17 in patients without comorbidity and adjusted HR $=1.75,95 \% \mathrm{CI}=1.11-2.77$ in patients with comorbidity, respectively).

The incident rates and HRs of IBDs stratified based on the follow-up period are presented in Table 3. The adjusted HRs of IBDs for patients with appendectomy relative to controls were 3.99 (95\% CI $=2.69-5.91)$, 2.67 (95\% CI $=1.64-4.35)$, and 1.74 (95\% CI $=1.14-2.66)$ in people with a follow-up time of $<3$, $3-6$, and $>6$ years, respectively. For UC and CD, the highest adjusted HR was observed in patients with a follow-up time of $<3$ years.

Table 4 presents the incidence and risk of UC and CD for the appendectomy cohort without appendicitis and with appendicitis compared with those for the non-appendectomy cohort. The incidence and risk of UC (13.4 vs. 2.77 per 10000 person years, adjusted $\mathrm{HR}=3.19,95 \% \mathrm{CI}=1.86-$ 5.50) and CD (14.8 vs. 2.15 per 10,000 person years, adjusted $\mathrm{HR}=6.13,95 \% \mathrm{CI}=3.54-10.6)$ were substantially higher in the appendectomy cohort without appendicitis than in the 
TABLE 3 | Incidence and adjusted hazard ratio of inflammatory bowel disease based on follow-up period for patients with appendectomy compared with controls.

\begin{tabular}{|c|c|c|c|c|c|c|c|c|}
\hline \multirow[b]{3}{*}{ Variables } & \multicolumn{6}{|c|}{ Appendectomy } & \multicolumn{2}{|c|}{ Compared to control } \\
\hline & \multicolumn{3}{|c|}{ Yes } & \multicolumn{3}{|c|}{ No } & \multirow[b]{2}{*}{ Crude HR (95\% Cl) } & \multirow[b]{2}{*}{ Adjusted $\mathrm{HR}^{\dagger}(95 \% \mathrm{Cl})$} \\
\hline & Events & PY & Rate $^{\#}$ & Events & PY & Rate $^{\#}$ & & \\
\hline \multicolumn{9}{|l|}{ All } \\
\hline \multicolumn{9}{|c|}{ Follow-up time, years } \\
\hline$<3$ & 131 & 678,513 & 19.3 & 31 & 685,753 & 4.52 & $4.26(2.88,6.31)^{\star \star \star}$ & $3.99(2.69,5.91)^{\star \star \star}$ \\
\hline $3-6$ & 64 & 504,262 & 12.7 & 22 & 512,187 & 4.30 & $2.96(1.82,4.80)^{\star \star \star}$ & $2.67(1.64,4.35)^{\star \star \star}$ \\
\hline$>6$ & 60 & 555,167 & 10.8 & 34 & 568,921 & 5.98 & $1.81(1.19,2.75)^{\star \star}$ & $1.74(1.14,2.66)^{\star}$ \\
\hline \multicolumn{9}{|c|}{ Ulcerative colitis (UC) } \\
\hline \multicolumn{9}{|c|}{ Follow-up time, years } \\
\hline$<3$ & 54 & & 7.96 & 15 & & 2.19 & $3.63(2.05,6.44)^{\star \star \star}$ & $3.30(1.85,5.88)^{\star \star \star}$ \\
\hline $3-6$ & 32 & & 6.35 & 11 & & 2.15 & $2.96(1.49,5.86)^{\star \star}$ & $2.67(1.34,5.34)^{\star *}$ \\
\hline$>6$ & 30 & & 5.40 & 23 & & 4.04 & $1.34(0.78,2.30)$ & $1.28(0.74,2.22)$ \\
\hline \multicolumn{9}{|c|}{ Crohn's disease (CD) } \\
\hline \multicolumn{9}{|c|}{ Follow-up time, years } \\
\hline$<3$ & 77 & & 11.4 & 16 & & 2.33 & $4.85(2.83,8.32)^{\star \star \star}$ & $4.58(2.67,7.87)^{\star \star \star}$ \\
\hline $3-6$ & 32 & & 6.35 & 11 & & 2.15 & $2.95(1.49,5.86)^{\star \star}$ & $2.65(1.33,5.29)^{\star \star}$ \\
\hline$>6$ & 30 & & 5.40 & 11 & & 1.93 & $2.80(1.40,5.58)^{\star \star}$ & $2.69(1.34,5.40)^{\star \star}$ \\
\hline
\end{tabular}

Rate $^{\#}$, Incidence rate per 10,000 person-years; Crude HR, relative hazard ratio; Adjusted HRt ${ }^{\dagger}$ adjusted hazard ratio after control for age, sex, and comorbidities of CAD, hypertension, diabetes, hyperlipidemia, CVA, heart failure, COPD, CKD, alcohol-related diseases, cirrhosis, and biliary stone.

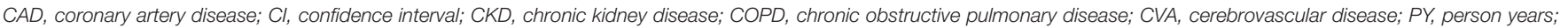

$S D$, standard deviation.

${ }^{\star} P<0.05,{ }^{\star \star} P<0.01,{ }^{\star \star \star} P<0.001$

TABLE 4 | Comparison of the HRs of ulcerative colitis and Crohn's disease among patients who underwent appendectomy with and without appendicitis and controls.

\begin{tabular}{|c|c|c|c|c|c|}
\hline Variable & $\mathbf{N}$ & Event & Rate $^{\#}$ & Crude HR (95\% Cl) & Adjusted $\mathrm{HR}^{\dagger}(95 \% \mathrm{Cl})$ \\
\hline \multicolumn{6}{|l|}{ Ulcerative colitis } \\
\hline Non-appendectomy & 246,562 & 49 & 2.77 & 1.00 & 1.00 \\
\hline \multicolumn{6}{|l|}{ Appendectomy } \\
\hline Without appendicitis & 21,996 & 19 & 13.4 & $4.81(2.83,8.16)^{\star \star \star}$ & $3.19(1.86,5.50)^{\star \star \star}$ \\
\hline With appendicitis & 224,566 & 97 & 6.08 & $2.19(1.55,3.09)^{\star \star \star}$ & $2.11(1.49,2.98)^{\star \star \star}$ \\
\hline \multicolumn{6}{|l|}{ Crohn's disease } \\
\hline Non- appendectomy & 246,562 & 38 & 2.15 & 1.00 & 1.00 \\
\hline \multicolumn{6}{|l|}{ Appendectomy } \\
\hline Without appendicitis & 21,996 & 21 & 14.8 & $6.77(3.97,11.5)^{\star \star \star}$ & $6.13(3.54,10.6)^{\star \star \star}$ \\
\hline With appendicitis & 224,566 & 118 & 7.39 & $3.43(2.38,4.95)^{\star \star \star}$ & $3.24(2.24,4.68)^{\star \star \star}$ \\
\hline
\end{tabular}

Rate ${ }^{\#}$, incidence rate per 10,000 person-years; Crude HR, relative hazard ratio; Adjusted $H R^{\dagger}$, adjusted hazard ratio after control for age, sex, and comorbidities of CAD, hypertension, diabetes, hyperlipidemia, CVA, heart failure, COPD, CKD, alcohol-related diseases, cirrhosis, and biliary stone.

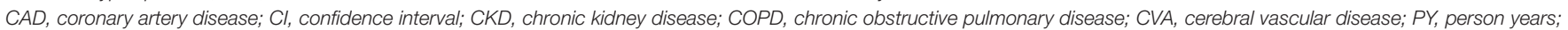

$S D$, standard deviation.

${ }^{* \star *} P<0.001$.

non-appendectomy cohort. However, the incidence and risk of UC (6.08 vs. 2.77 per 10,000 person years, adjusted $\mathrm{HR}=$ 2.11, $95 \% \mathrm{CI}=1.49-2.98)$ and $\mathrm{CD}$ (7.39 vs. 2.15 per 10,000 person years, adjusted $\mathrm{HR}=3.24,95 \% \mathrm{CI}=2.24-4.68)$ were higher in the appendectomy cohort with appendicitis than in the non-appendectomy cohort.

Table 5 lists the incidence and risk of $\mathrm{UC}$ and $\mathrm{CD}$ among patients of various ages with appendectomy compared with the corresponding controls. The incidence and risk of $\mathrm{UC}$ and $\mathrm{CD}$ were significantly higher in the appendectomy cohort irrespective of when appendectomy was conducted than in the corresponding controls.

Figure 1 shows that the cumulative incidence of IBDs in patients with appendectomy was significantly higher than that of the comparison group $(P$-value $<0.001)$. 
TABLE 5 | Comparison of the HR for ulcerative colitis and Crohn's disease among patients who underwent appendectomy at different ages.

\begin{tabular}{|c|c|c|c|c|c|c|c|c|}
\hline \multirow[b]{2}{*}{ Variables } & \multicolumn{6}{|c|}{ Appendectomy } & \multicolumn{2}{|c|}{ Compared to control } \\
\hline & Events & PY & Rate $^{\#}$ & Events & PY & Rate $\#$ & Crude HR (95\% Cl) & Adjusted $\mathrm{HR}^{\dagger}(95 \% \mathrm{Cl})$ \\
\hline Ulcerative colitis (UC) & 49 & 176,6861 & 2.77 & 116 & $1,737,942$ & 6.67 & $2.40(1.72,3.36)^{\star \star \star}$ & $2.23(1.59,3.12)^{\star \star \star}$ \\
\hline \multicolumn{9}{|l|}{ Age, years } \\
\hline$>50$ & 26 & 502,128 & 5.18 & 54 & 470,819 & 11.5 & $2.21(1.39,3.53)^{\star \star \star}$ & $1.89(1.17,3.04)^{\star \star}$ \\
\hline Crohn's disease (CD) & 38 & 176,6861 & 2.15 & 139 & $1,737,942$ & 8.00 & $3.71(2.59,5.31)^{\star \star \star}$ & $3.48(2.42,4.99)^{\star \star \star}$ \\
\hline \multicolumn{9}{|l|}{ Age, years } \\
\hline$\leq 34$ & 14 & 704,429 & 1.99 & 66 & 713,152 & 9.25 & $2.31(1.26,4.22)^{\star \star \star}$ & $2.17(1.18,3.99)^{\star}$ \\
\hline $35-49$ & 5 & 560,303 & 0.89 & 37 & 553,971 & 6.68 & $3.42(1.55,7.52)^{\star \star}$ & $3.41(1.54,7.54)^{\star *}$ \\
\hline
\end{tabular}

Rate\#, Incidence rate per 10,000 person years; Crude HR, relative hazard ratio; Adjusted HRt, adjusted hazard ratio after control for sex and comorbidities of CAD, hypertension, diabetes, hyperlipidemia, CVA, heart failure, COPD, CKD, alcohol-related diseases, cirrhosis, and biliary stone.

$C A D$, coronary artery disease; $\mathrm{Cl}$, confidence interval; $C K D$, chronic kidney disease; COPD, chronic obstructive pulmonary disease; CVA, cerebrovascular disease; PY, person years; $S D$, standard deviation.

${ }^{\star} P<0.05,{ }^{* *} P<0.01,{ }^{* * *} P<0.001$

\section{DISCUSSION}

The nationwide cohort study indicated that the appendectomy cohort exhibited a higher incidence rate of IBDs than did the comparison cohort regardless of age, sex, and comorbidity. The appendectomy cohort had a 2.78 -fold higher adjusted HR of IBDs (2.23-fold higher adjusted HR of UC and 3.48-fold higher adjusted $\mathrm{HR}$ of $\mathrm{CD}$ ) than did the comparison cohort. Our results were comparable with a large case-control study, which showed a 1.6 and 2.5 times higher risk of $\mathrm{UC}$ and $\mathrm{CD}$ after appendectomy based on inpatient records from Veterans Affairs hospitals in the United States (15).

Andersson et al. $(14,16)$ reported that appendectomy is associated with an increased $C D$ risk but a decreased risk of subsequent UC through an observational study of the Swedish Inpatient Registry. However, Andersson et al. indicated that only those patients who underwent appendectomy $<20$ years decreased a risk of UC development. Our study participants excluding patients $<20$ years may partially explained the controversial finding on the risk of UC. A retrospective casecontrol study from two Chinese hospitals did not show a significant negative association between appendectomy and UC occurrence (17).

Although IBD prevalence is higher in Western countries than in Taiwan, the incidence and prevalence of IBD have been rapidly increasing in Taiwan $(10,18,19)$. The exact IBD pathogenesis remains to be elucidated, although IBD is generally considered to be related to genetic susceptibility and environmental factors $(20,21)$. Epigenetic modifications influenced by gut microbiota and diet may pay a role in IBD development (22, 23). Western-style diet may predispose people to IBD (24). Many people in Taiwan have shifted to a Western-style diet, which may be associated with an increased IBD incidence in Taiwan (25).

The vermiform appendix contains substantial lymphoid tissue and may act as a microbial reservoir for beneficial microbes to reinoculate the gut if required (6). The appendix provides a complex microbial environment for the homeostasis of immunologically and metabolically active organs $(26,27)$. Therefore, the appendix may serve as an organ to induce and maintain the mucosal immune system. An animal study indicated that appendectomy impairs intestinal immunity, which may be related to IBD development (28). Gut microbiota alteration in IBD may activate immune responses, interfere in homeostasis, cause tissue injury, decrease the mucus layer, and enhance microbial penetration and bacterial persistence in the gut tissue (29).

Anderson et al. conducted a cohort study by recruiting patients who underwent appendectomy from the inpatient registry database of the Swedish National Board of Health and Welfare and indicated that appendectomy due to appendicitis is associated with a decreased risk of subsequent UC (16). In contrast, no significant risk difference of UC was noted between appendectomy patients without inflammatory appendix and non-appendecomy controls (16). Frisch et al. suggested that patients aged $<20$ years at appendectomy for appendicitis or mesenteric lymphadenitis were related to reduced risk of UC development in Sweden and Denmark cohort studies (30). However, our study showed that the appendectomy cohort had increased UC risk regardless of whether the patient had appendicitis. Moreover, the UC risk was significantly higher in the appendectomy cohort than the non-appendectomy cohort irrespective of the age at appendectomy in the adulthood. The difference 


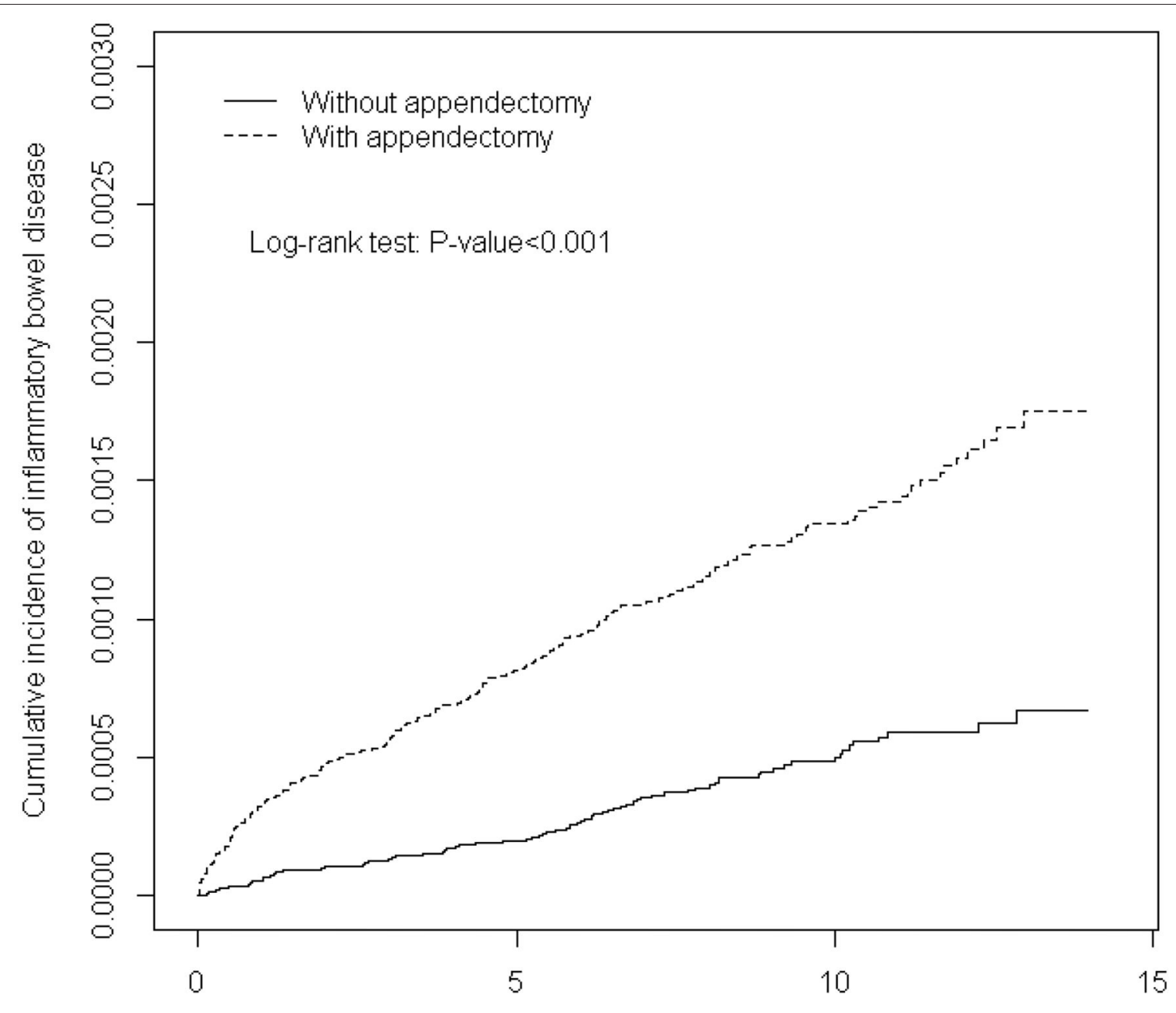

years

FIGURE 1 | Cummulative incidence of inflammatory bowel disease in patients with appendectomy and comparison patients.

between Western studies and our study may be due to racial variances and dysregulated gut microbiota due to environmental insults (31).

The appendectomy cohort, irrespective of appendicitis, exhibited a considerably increased CD risk compared with the non-appendectomy cohort. The findings were consistent with those of previous studies (14). In addition, CD risk was significantly higher in the appendectomy cohort than in the nonappendectomy cohort irrespective of the age at appendectomy. The incidence rate of CD after appendectomy was the highest in the first 3 years. The risk of subsequent $\mathrm{CD}$ in the appendectomy cohort remained considerably higher than in the non-appendectomy cohort after 6 years following appendectomy.

This longitudinal cohort study estimated the incidence and risk of IBD in a large Asian population that underwent appendectomy. The study cohort could be followed throughout the follow-up period through NHIRD records because the NHI is mandatory and universal in Taiwan. However, several limitations should be noted when interpreting the results. First, coexistence of IBD and appendicitis was noted at appendectomy, which would be diagnosed by the pathologist. Second, the Western dietary habit of the study participants was not investigated in the current study. However, we controlled for the comorbidities of hyperlipidemia, diabetes, and hypertension to mediate the effect of a Western-style diet $(32,33)$. Third, familial history of IBD and smoking behavior in the study participants were not available in the NHIRD, which may have influenced the study results.

In summary, a nationwide cohort study indicated that the incidence and risk of $\mathrm{CD}$ and $\mathrm{UC}$ are higher in the appendectomy cohort than in the non-appendectomy cohort. The results highlight that clinicians must be aware that Asian patients undergoing appendectomy may develop CD or UC. 


\section{DATA AVAILABILITY STATEMENT}

The original contributions presented in the study are included in the article/supplementary material, further inquiries can be directed to the corresponding author.

\section{ETHICS STATEMENT}

The studies involving human participants were reviewed and approved by the Institutional Review Board of China Medical University Hospital (CMUH-104-REC2-115). The ethics committee waived the requirement of written informed consent for participation.

\section{REFERENCES}

1. Tannoury J, Abboud B. Treatment options of inflammatory appendiceal masses in adults. World J Gastroenterol. (2013) 19:3942-50. doi: 10.3748/wjg.v19.i25.3942

2. Addiss DG, Shaffer N, Fowler BS, Tauxe RV. The epidemiology of appendicitis and appendectomy in the united states. Am J Epidemiol. (1990) 132:91025. doi: 10.1093/oxfordjournals.aje.a115734

3. Lin KB, Chan CL, Yang NP, Lai RK, Liu YH, Zhu SZ, et al. Epidemiology of appendicitis and appendectomy for the low-income population in Taiwan, 2003-2011. BMC Gastroenterol. (2015) 15:18. doi: 10.1186/s12876-015-0242-1

4. Vitetta L, Chen J, Clarke S. The vermiform appendix: an immunological organ sustaining a microbiome inoculum. Clin Sci. (2019) 133:1-8. doi: 10.1042/CS20180956

5. Kooij IA, Sahami S, Meijer SL, Buskens CJ, Te Velde AA. The immunology of the vermiform appendix: a review of the literature. Clin Exp Immunol. (2016) 186:1-9. doi: 10.1111/cei.12821

6. Randal Bollinger R, Barbas AS, Bush EL, Lin SS, Parker W. Biofilms in the large bowel suggest an apparent function of the human vermiform appendix. J Theor Biol. (2007) 249:826-31. doi: 10.1016/j.jtbi.2007.08.032

7. Im GY, Modayil RJ, Lin CT, Geier SJ, Katz DS, Feuerman M, et al. The appendix may protect against clostridium difficile recurrence. Clin Gastroenterol Hepatol. (2011) 9:1072-7. doi: 10.1016/j.cgh.2011.06.006

8. Kuenzig ME, Benchimol EI, Lee L, Targownik LE, Singh H, Kaplan GG, et al. The impact of inflammatory bowel disease in Canada 2018: direct costs and health services utilization. J Can Assoc Gastroenterol. (2019) 2(Suppl. 1):S17-33. doi: 10.1093/jcag/gwy055

9. Kim YS, Jung SA, Lee KM, Park SJ, Kim TO, Choi $\mathrm{CH}$, et al. Impact of inflammatory bowel disease on daily life: an online survey by the Korean association for the study of intestinal diseases. Intest Res. (2017) 15:33844. doi: 10.5217/ir.2017.15.3.338

10. Yen HH, Weng MT, Tung CC, Wang YT, Chang YT, Chang $\mathrm{CH}$, et al. Epidemiological trend in inflammatory bowel disease in taiwan from 2001 to 2015: a nationwide populationbased study. Intest Res. (2019) 17:5462. doi: $10.5217 /$ ir.2018.00096

11. Ramos GP, Papadakis KA. Mechanisms of disease: inflammatory bowel diseases. Mayo Clin Proc. (2019) 94:15565. doi: 10.1016/j.mayocp.2018.09.013

12. Frisch M, Johansen C, Mellemkjaer L, Engels EA, Gridley G, Biggar RJ, et al. Appendectomy and subsequent risk of inflammatory bowel diseases. Surgery. (2001) 130:36-43. doi: 10.1067/msy.2001.115362

13. Gardenbroek TJ, Eshuis EJ, Ponsioen CI, Ubbink DT, D'Haens GR, Bemelman WA. The effect of appendectomy on the course of ulcerative colitis: a systematic review. Colorectal Dis. (2012) 14:545-3. doi: 10.1111/j.1463-1318.2011.02600.x

14. Andersson RE, Olaison G, Tysk C, Ekbom A. Appendectomy is followed by increased risk of crohn's disease. Gastroenterology. (2003) 124:406. doi: 10.1053 /gast.2003.50021

\section{AUTHOR CONTRIBUTIONS}

W-SC: conception and design. W-SC, SC, C-YH, and C-LL: administrative support, collection and assembly of data, data analysis and interpretation, and manuscript writing. All authors contributed to the article and approved the submitted version.

\section{FUNDING}

This study was supported in part by Taiwan Ministry of Health and Welfare Clinical Trial Center (MOHW109-TDUB-212-114004). The funders had no role in study design, data collection and analysis, decision to publish, or preparation of the manuscript.

15. Frisch M, Gridley G. Appendectomy in adulthood and the risk of inflammatory bowel diseases. Scand J Gastroenterol. (2002) 37:11757. doi: $10.1080 / 003655202760373380$

16. Andersson RE, Olaison G, Tysk C, Ekbom A. Appendectomy and protection against ulcerative colitis. N Eng J Med. (2001) 344:80814. doi: 10.1056/NEJM200103153441104

17. Chen D, Ma J, Luo S, Lu L, Wan X, Ben Q. Effects of appendectomy on the onset and course of ulcerative colitis in Chinese patients. Gastroenterol Res Pract. (2018) 2018:2927891. doi: 10.1155/2018/2927891

18. Ng SC, Shi HY, Hamidi N, Underwood FE, Tang W, Benchimol EI, et al. Worldwide incidence and prevalence of inflammatory bowel disease in the 21st century: a systematic review of population-based studies. Lancet. (2018) 390:2769-78. doi: 10.1016/S0140-6736(17)32448-0

19. Ng SC, Bernstein CN, Vatn MH, Lakatos PL, Loftus EV Jr, Tysk C, et al. Geographical variability and environmental risk factors in inflammatory bowel disease. Gut. (2013) 62:630-49. doi: 10.1136/gutjnl-2012-303661

20. Turpin W, Goethel A, Bedrani L, Croitoru Mdcm K. Determinants of IBD heritability: genes, bugs, and more. Inflamm Bowel Dis. (2018) 24:113348. doi: 10.1093/ibd/izy085

21. Liu JZ, Anderson CA. Genetic studies of crohn's disease: past, present and future. Best Pract Res Clin Gastroenterol. (2014) 28:373-86. doi: 10.1016/j.bpg.2014.04.009

22. Krautkramer KA, Kreznar JH, Romano KA, Vivas EI, Barrett-Wilt GA, Rabaglia ME, et al. Diet-microbiota interactions mediate global epigenetic programming in multiple host tissues. Mol Cell. (2016) 64:98292. doi: 10.1016/j.molcel.2016.10.025

23. Sartor RB, Wu GD. Roles for intestinal bacteria, viruses, and fungi in pathogenesis of inflammatory bowel diseases and therapeutic approaches. Gastroenterology. (2017) 152:327-39.e4. doi: 10.1053/j.gastro.2016.10.012

24. Castro F, de Souza HSP. Dietary composition and effects in inflammatory bowel disease. Nutrients. (2019) 11:1398. doi: 10.3390/nu11061398

25. Pan WH, Wu HJ, Yeh CJ, Chuang SY, Chang HY, Yeh NH, et al. Diet and health trends in taiwan: comparison of two nutrition and health surveys from 1993-1996 and 2005-2008. Asia Pacific J Clin Nutr. (2011) 20:238-50. doi: 10.6133/apjen.2011.20.2.14

26. Guinane CM, Tadrous A, Fouhy F, Ryan CA, Dempsey EM, Murphy B, et al. Microbial composition of human appendices from patients following appendectomy. mBio. (2013) 4:e00366-12. doi: 10.1128/mBio.00366-12

27. Kundu P, Blacher E, Elinav E, Pettersson S. Our gut microbiome: the evolving inner self. Cell. (2017) 171:1481-93. doi: 10.1016/j.cell.2017.11.024

28. Dasso JF, Howell MD. Neonatal appendectomy impairs mucosal immunity in rabbits. Cell Immunol. (1997) 182:29-37. doi: 10.1006/cimm.1997.1216

29. Zuo T, Ng SC. The gut microbiota in the pathogenesis and therapeutics of inflammatory bowel disease. Front. Microbiol. (2018) 9:2247. doi: 10.3389/fmicb.2018.02247

30. Frisch M, Pedersen BV, Andersson RE. Appendicitis, mesenteric lymphadenitis, and subsequent risk of ulcerative colitis: cohort studies in Sweden and Denmark. BMJ. (2009) 338:b716. doi: 10.1136/bmj.b716 
31. Abegunde AT, Muhammad BH, Bhatti O, Ali T. Environmental risk factors for inflammatory bowel diseases: evidence based literature review. World J Gastroenterol. (2016) 22:6296-317. doi: 10.3748/wjg.v22.i2 7.6296

32. Beigrezaei S, Ghiasvand R, Feizi A, Iraj B. Relationship between dietary patterns and incidence of type 2 diabetes. Int J Prev Med. (2019) 10:122. doi: 10.4103/ijpvm.IJPVM_206_17

33. Wang D, He Y, Li Y, Luan D, Yang X, Zhai F, et al. Dietary patterns and hypertension among chinese adults: a nationally representative crosssectional study. BMC Public Health. (2011) 11:925. doi: 10.1186/1471-2458$11-925$
Conflict of Interest: The authors declare that the research was conducted in the absence of any commercial or financial relationships that could be construed as a potential conflict of interest.

Copyright (c) 2021 Chung, Chung, Hsu and Lin. This is an open-access article distributed under the terms of the Creative Commons Attribution License (CC BY). The use, distribution or reproduction in other forums is permitted, provided the original author(s) and the copyright owner(s) are credited and that the original publication in this journal is cited, in accordance with accepted academic practice. No use, distribution or reproduction is permitted which does not comply with these terms. 